Dipublikasikan

Badan Pelaksana Kuliah Kerja Nyata

Universitas Lampung

Sekretariat Badan Pelaksana Kuliah Kerja Nyata, Universitas Lampung

Ji. Prof. Dr. Scemantri Brojonegoro No. 1, Bandar Lampung 35145.

\title{
PELATIHAN DIGITALISASI UMKM DAN PEMBUATAN AKUN E-COMMERCE
}

\author{
Aldi Dharma Putra ${ }^{*}$, Budhi Setiawan ${ }^{1}$, Intan Pubiyanti' ${ }^{1}$, Muhammad \\ Hafidh Hibatulloh ${ }^{1}$, Niken Ayu Ambar Saputri ${ }^{1}$, Wahyu Susilowati \\ Sepsiana ${ }^{1,2}$ RA. Diana Widyastuti
}

\author{
${ }^{1}$ Mahasiswa KKN Periode 12021 Universitas Lampung ${ }^{2}$ Program Studi Ekonomi \\ ${ }^{2}$ Program Studi Agronomi \& Hortikultura/FP, Universitas Lampung \\ Penulis Korespodensi: ${ }^{1}$ aldidharmaputra10@gmail.com
}

\begin{abstract}
Abstrak
Tujuan Kegiatan Pelatihan digitalisasi Usaha Mikro Kecil Menengah (UMKM) serta pembuatan akun E-Commerce Kelompok Wanita Tani (KWT) adalah membantu masyarakat UMKM KWT Usaha Mandiri dalam menyelesaikan masalah-masalah yang dihadapinya dalam upaya mengembangkan usaha, mulai dari aspek produksi maupun manajemen usaha hingga yang terutama adalah dalam segi pemasaran berbasis digitalisasi UMKM yang diharapkan akan tercipta kemandirian secara ekonomi dan meningkatnya pendapatan usaha mereka. Target Khusus dalam kegiatan Pelatihan digitalisasi UMKN serta Pembuatan akun E-Commerce KWT adalah dihasilkannya: 1) Progaram dalam produksi; 2) Program dalam pengelolaan Keuangan; dan 3) Program dalam pemasaran. Pelatihan digitalisasi UMKM dan pembuatan akun E-Commerce dilaksanakan pada tanggal 18 Febuari dan 02 Maret 2021. Pelatihan dan pembuatan akun ECommerce ini ditujukan untuk UMKM KWT Usaha Mandiri, Kenanga, dan Cempaka. ECommerce yang dibuat diantaranya Akun Shoppe, Facebook dan Instagram. Diharapkan dengan adanya Pelatihan digitalisasi UMKM serta Pembuatan akun E-Commerce ini akan terbentuk masyarakat yang berwirausaha secara inovatif dalam proses pemasaran, Mandiri dan tanggap terhadap permintaan pasar sehingga akan memberikan kontribusi yang positif terhadap masyarakat dan lingkungannya.
\end{abstract}

Kata kunci: Usaha Mikro Kecil Menengah, E-Commerce.

\begin{abstract}
The purpose of training activities for digitizing Micro, Small and Medium Enterprises (MSMEs) and creating an E-Commerce account for the "Kelompok Wanita Tani" (KWT) is to help the KWT UKM community in solving the problems they face in an effort to develop a business, ranging from aspects of production and business management to especially in terms of marketing based on digitalization of MSMEs, which are expected to create economic independence and increase their business income. Specific targets in the UMKN digitalization training and KWT E-Commerce account creation are: 1) production programs; 2) Programs in Financial Management; and 3) Programs in marketing. Training on digitizing MSMEs and creating E-Commerce accounts was held on February 18 and March 02, 2021. This training and creation of E-Commerce accounts is aimed at KWT SMEs for Mandiri, Kenanga, and Cempaka businesses. E-Commerce made includes Shoppe, Facebook and Instagram accounts. It is hoped that with the training on digitizing MSMEs and creating E-Commerce accounts, people will form innovative entrepreneurs in the marketing process, independent and responsive to market demands so that they will make a positive contribution to society and the environment.
\end{abstract}

Keywords: digitizing Micro, Small and Medium Enterprises, E-Commerce 


\section{Jurnal Pengabdian Kepada Masyarakat BUGUH}

Dipublikasikan

Badan Pelaksana Kuliah Kerja Nyata

Universitas Lampung

Sekretariat Badan Pelaksana Kuliah Kerja Nyata, Universitas Lampung.

Il. Prof. Dr. Scemantri Brojonegoro No. 1, Bandar Lampung 35145.

\section{Pendahuluan}

Kemajuan teknologi adalah sesuatu yang tidak bisa dihindari dalam kehidupan saat ini karena kemajuan teknologi akan berjalan sesuai dengan kemajuan ilmu pengetahuan. Setiap inovasi diciptakan untuk memberikan manfaat positif, memberikan banyak kemudahan, serta memberi cara baru dalam melakukan aktivitas bagi kehidupan manusia. Digitalisasi bisnis sudah menjadi salah satu strategi untuk dapat menjangkau pasar yang lebih luas. Dengan adanya teknologi dan jangkauan pasar yang lebih luas maka muncul yang disebuyt dengan Digital Marketing. Hal ini dapat didefinisikan sebagai kegiatan marketing, termasuk branding, yang menggunakan berbagai media berbasis web. Digital marketing merupakan pemasaran dengan menggunakan penerapan teknologi secara digital. Salah satu bentuk marketing digital dengan menggunakan media elektronik atau internet adalah internet marketing (e-marketing) (Qamari et al., 2021).

UMKM (Usaha Mikro Kecil dan Menegah) di Indonesia menjadi salah satu sektor usaha yang cukup mendominasi dijalankan oleh pelaku usaha. Berdasarkan data BPS didapatkan bahwa perkembangan UMKM di Indonesia pada 2013 sampai 2015 mengalami kenaikan untuk industri mikro namun perkembangan industri kecil mengalami penurunan setiap tahun (Idah \& Pinilih, 2020). Pelaku bisnis mulai menggunakan teknologi informasi dan telekomunikasi untuk menjalankan maupun menunjang kegiatan bisnis mereka. Pergerakan dan perubahan cara berbisnis yang kian cepat ke arah digitalisasi ini memaksa pelaku bisnis untuk beradaptasi mengikuti perubahan tersebut. Bagi perusahaan besar, perubahan pola bisnis yang mengarah pada proses digitalisasi ini tidak terlalu mengalami kendala dikarenakan dengan karakteristik perusahaan besar yang memiliki sumber daya yang cukup baik. Namun, bagi UMKM proses digitalisasi ini akan membutuhkan banyak persiapan.

Tujuan dilaksanakannya pelatihan digitalisasi bisnis UMKM adalah untuk menjawab permasalahan mitra PKM, yaitu pengusaha UMKM Kelompok Wanita Tani Usaha Mandiri, Kenanga, dan Cempaka. Adapun permasalahan mitra adalah kurangnya pengetahuan dan wawasan mitra seputar bisnis online. Maka dari itu kami berusaha untuk melakukan suatu pelatihan dan pembuatan media akun E - Commerce sebagai penunjang kegiatan bisnis pada UMKM Kelompok Wanita Tani Usaha Mandiri, Kenanga, dan Cempaka. Berdasarkan hal tersebut Kegiatan ini berusaha untuk merumuskan strategi pengembangan digitalisasi UMKM guna mendukung perkembangan UMKM serta sebagai bahan masukan bagi pelaku UMKM dalam menerapkan digitalisasi dalam proses bisnisnya.

\section{Bahan dan Metode}

Metode pendekatan pada pelaksanaan kegiatan pengabdian masyarakat ini yaitu pendekatan langsung kepada masyarakat. Pelaksanaan kegiatan pengabdian masyarakat pada bagian Pelatihan Digitalisasi UMKM dilakukan melalui kerjasama dengan masyarakat dan diskusi mengenai produk yang akan dipasarkan melalui E-Commerce. Kegiatan ini dilaksanakan oleh Pengurus KWT Usaha Mandiri, KWT Kenanga, KWT Cempaka di Desa Waspada. E-Commerce yang dipakai pada kegiatan ini adalah Berdasarkan 6 golongan E-Commerce yang tersedia tersebut, maka Shopee, Facebook dan Instagram termasuk dalam Business to consumer (B2C), dimana jenis ecommerce ini, menjual produk atau jasa kepada konsumen, seperti toko Online. 


\section{Jurnal Pengabdian Kepada Masyarakat BUGUH}

Dipublikasikan

Badan Pelaksana Kuliah Kerja Nyata

Universitas Lampung

Sekretariat Badan Pelaksana Kuliah Kerja Nyata, Universitas Lampung,

Il. Prof. Dr. Scemantri Brojonegoro No. 1, Bandar Lampung 35145.

\section{Hasil dan Pembahasan}

Kuliah Kerja Nyata (KKN) Mandiri Putra Daerah dilaksanakan sesuai dengan jadwal yang sudah di tentukan dan telah disusun. Adapun kegiatan yang dilaksanakan sebagai berikut:

Kegiatan Kuliah Kerja Nyata (KKN) Mandiri Putra Daerah diawali dengan melaksanakan kegiatan Pra-KKN pada tanggal 20-21 Desember 2020 yang berupa kunjungan langsung ke desa tempat pelaksanaan KKN. Tujuan dari kegiatan ini adalah untuk memberikan gambaran desa secara langsung dan untuk melakukan pengamatan secara langsung melalui informasi yang di dapatkan dari perangkat desa maupun masyarakat guna perumusan program kerja yang dilaksanakan saat KKN. Kuliah Kerja Nyata (KKN) Mandiri Putra Daerah ini telah dilaksanakan oleh mahasiswa di Desa Waspada, Kecamatan Sekincau, Kabupaten Lampung Barat dan dimulai dari tanggal 1 Februari 2021 hingga 12 Maret 2021. Mahasiswa peserta Kuliah Kerja Nyata (KKN) Mandiri Putra Daerah diwajibkan untuk membuat pelaporan kegiatan dan aktivitas harian berupa penjelasan aktivitas yang dilakukan disertai dengan foto dan video. Pemantauan secara real-time dilakukan secara jarak jauh melalui penggunaan media daring oleh dosen pendamping lapangan.

Kegiatan Kuliah Kerja Nyata (KKN) Mandiri Putra Daerah yang digelar bersamaan dengan merebaknya pandemi covid-19 menuntut mahasiswa yang melaksanakan KKN didesa tersebut untuk terus memberikan hal yang dapat membantu desa dalam memberikan informasi. Hal tersebut dapat terkait dengan, penyuluhan mengenai betapa pentingnya menjaga kesehatan, sosialisasi bahaya narkoba, penting nya pemanfaatan lahan pangan keluarga dan informasi lainnya. Selain dari hal tersebut, didisi kami Mahasiswa Kuliah Kerja Nyata (KKN) Mandiri Putra Daerah juga membantu dalam memberikan solusi terkait dengan pengembangan usaha yang dilakukan Kelompok Wanita Tani (KWT) Desa Waspada dalam melakukan pemasaran produk agar dapat bersaing di pasar luar, meskipun dalam kondisi yang berada ditengah Pandemi Covid-19. Jadi, dengan adanya program kerja Pelatihan Digitalisasi UMKM dan pembuatan akun ECommerce maka hal ini dapat membantu produk Kelompok Wanita Tani (KWT) Desa Waspada untuk terus bertahan dalam pemasarannya walaupun terhalang dengan keadaan pandemi Covid-19. Sebab, dengan adanya Pelatihan Digitalisasi UMKM dan pembuatan akun E-Commerce maka kita sudah menjadi salah satu Mahasiswa yang dapat berperan sebagai Duta Covid-19 dengan memberikan solusi terhadap UMKM agar dapat memasarkan produknya sesuai dengan peraturan pemerintah terkait Social Distancing. Hal ini, dapat dilihat dimana dalam proses pemasarannya tidak ada pemasaran secara konvensiaonal antara penjual dan pembeli produk.

Desa Waspada, Kecamatan Sekincau, Kabupaten Lampung Barat ini merupakan desa yang memiliki 3 produk olahan pangan yang dihasilkan dari kegiatan Kelompok Wanita Tani (KWT). Dimana, setiap Kelompok Wanita Tani (KWT) Desa Waspada menciptakan 1 produk pangan. 3 kelompok KWT tersebut diantaranya ialah :

1. Kelompok Wanita Tani (KWT) Usaha Mandiri menciptakan Produk Kopi Bubuk Tugu Waspada

2. Kelompok Wanita Tani (KWT) Kenanga menciptakan Produk Jajan Pasar seperti (Cucur, lapis, bolu, slimpok makanan khas kampung dan jajanan pasar lainnya)

3. Kelompok Wanita Tani (KWT) Cempaka menciptakan Produk Dodol Labu, Dodol Kopi, Dodol Tomat Desa Waspada 
Dipublikasikan

Badan Pelaksana Kuliah Kerja Nyata

Universitas Lampung

Sekretariat Badan Pelaksana Kuliah Kerja Nyata, Universitas Lampung.

Il. Prof. Dr. Scemantri Brojonegoro No. 1, Bandar Lampung 35145.

Dengan adanya kegiatan Kelompok Wanita Tani (KWT), Kami Mahasiswa Kuliah Kerja Nyata $(\mathrm{KKN})$ Mandiri Putra Daerah sangat banyak belajar berkenaan dengan produk yang dihasilkan. Salah satu contohnya, pada Produksi Kopi Bubuk Tugu Waspada Kami banyak melihat proses pengolahannya. Mulai dari penjemuran, penggilingan kopi menjadi biji, Dilakukan penyangraian kopi, digilingnya kopi menjadi bubuk, sampai pada tahap proses pengemasan kopi. Melihat pengolahan-pengolahan tersebut, membuat kami selaku Mahasiswa Kuliah Kerja Nyata (KKN) Mandiri Putra Daerah bertanya-tanya terkait dengan pemasaran yang dilakukan oleh Kelompok Wanita Tani (KWT) tersebut. Hal ini karena melihat banyaknya stok produk kopi yang terdapat dietalase penjualan, yang dirasa terkendala dalam hal pemasarannya atau pemasaran yang dirasa kurang baik sehingga menyebabkan Stok kopi bertambah namun penjualan menurun. Setelah Kami mencari tahu lebih dalam, ternyata permasalahan yang terjadi yaitu berakar pada metode penjualannya. Dimana, pada metode pemasaran yang digunakan saat itu merupakan metode pemasaran konvensional. Pemasaran konvensional adalah salah satu jenis pemasaran yang dilakukan secara langsung (Non-Online), sehingga pembeli mendatangi langsung sipenjual secara tatap muka dan sebaliknya.

Semakin berkembang pesatnya kemajuan IPTEK (Ilmu Pengetahuan Teknologi dan Komunikasi) membuat pemasaran konvensional dirasa hanya bergerak secara regresif. Hal tersebut karena, pemasaran konvensional telah tergeser oleh pemasaran yang memberdayakan IPTEK sebagai sarana pemasaran yang efisien dan efektif. Contohnya seperti pemasaran Online dengan menggunakan media handphone dan aplikasi sebagai tempat pemasaran. Adanya pemasaran Online, membuata pemasaran yang dahuku bersifat konvensional kini lambat laun beralih dengan internet. Era digital telah memberikan banyak perubahan pada segala aspek kehidupan. Keunggulan yang dapat dirasakan dari adanya pemasaran Online atau digital marketing adalah :

1. Dapat menjangkau konsumen lebih luas

Hal ini karena , media digital tidak mengenal batasan ruang. Bahkan Internet dapat menembus batas-batas suatu negara yang artinya suatu pesan yang telah diunggah keinternet dapat dikonsumsi oleh khalayak dari seluruh dunia. Oleh sebab itu, jika kita menyampaikan informasi terkait produk dan promosi yang kita lakukan, maka hal tersebut dapat menjangkau pemasaran yang lebih luas tidak hanya lokal, tetapi juga nasional bahkan global.

2. Hasil Terukur

Salah satu keistimewaan dari Pemasaran Online atau Digital Marketing adalah hasilnya lebih mudah untuk diukur. Hal ini karena, pemasaran digital melalui media digital berbasis data dapat memudahkan pemasar untuk melakukan monitoring proses pemasaran.

3. Penyampaian Informasi Lebih Cepat

Hal ini karena data digital lebih mudah diganti dan diperbarui. Oleh karena itu pesan atau iklan yang disampaikan melalui media digital lebih mudah untuk diperbarui. Selain lebih mudah, pembaharuan informasi juga lebih cepat dilakukan. Misalnya, informasi terkait produk atau promosi yang disampaikan melalui website resmi ingin diubah, maka bisa dilakukan perubahan saat itu juga.

4. Biaya Yang Dikeluarkan Lebih Murah

Kegiatan pemasaran melalui media digital terbilang relatif lebih murah dibandingkan dengan metode konvensional .

Melihat beberapa keuntungan yang didapatkan dari Pemasaran Online atau Digital Marketing, membuat Kami Mahasiswa Kuliah Kerja Nyata (KKN) Mandiri Putra Daerah 


\section{Jurnal Pengabdian Kepada Masyarakat}

\section{Dipublikasikan}

\section{BUGUH}

Badan Pelaksana Kuliah Kerja Nyata

Universitas Lampung

Sekretariat Badan Pelaksana Kuliah Kerja Nyata, Universitas Lampung.

Il. Prof. Dr. Scemantri Brojonegoro No. 1, Bandar Lampung 35145.

berprogres untuk menjalankan program kerja berkenaan dengan Pelatihan Digitalisasi UMKM dan Pembuatan Akun E-Commerce sebagai jalan terbaik untuk mengatasi permasalahan pasar dari produk-produk yang telah diciptakan. Sehingga penjualan produk kelak akan lebih mudah dan lebih efisien serta efektif.

Pada Pelatihan Digitalisasi yang dilaksanakan di Desa Waspada, Kecamatan Sekincau, Kabupaten Lampung Barat menerapkan langsung proses pembuatan account media sosial dan e commerce yang akan digunakan untuk memudahkan masyarakat khususnya anggota Kelompok Wanita Tani (KWT) yang ada di Desa Waspada, berikut merupakan tahapan dan langkah pembuatan account email, Shopee, Instagram \& Facebook. Contoh saja pada KWT Usaha Mandiri (Kopi Bubuk Tugu Waspada)

KWT Usaha Mandiri menjual bubuk kopi sebagai produk unggulan mereka, kopi bubuk tersebut diolah secara baik dan memperhatikan kualitas serta rasa yang akan dihasilkan sebelum sampai di tangan konsumen. Produk kopi inilah yang akan dipasarkan melalui digital marketing ( Facebook, Instagram, Shopee).

a. Pembuatan account e-mail.

\section{Langkah 1}

Pengisian Data

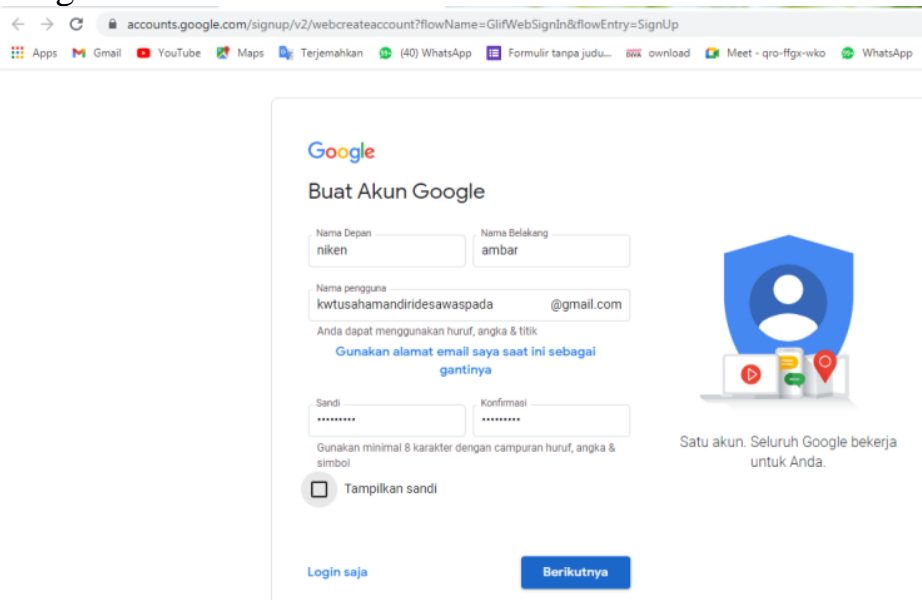

Gambar 1. Langkah pengisian data email 


\section{Jurnal Pengabdian Kepada Masyarakat}

\section{BUGUH}

Dipublikasikan

Badan Pelaksana Kuliah Kerja Nyata

Universitas Lampung

Sekretariat Badan Pelaksana Kuliah Kerja Nyata, Universitas Lampung.

Jt. Prof. Dr. Scemantri Brojonegoro No. 1, Bandar Lampung 35145.

\section{Langkah 2}

Pengisian Informasi Pribadi

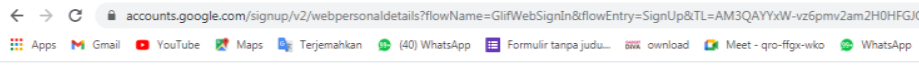

Google

Selamat datang di Google

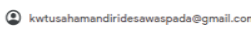

$$
\text { - Nomor telepon (opsional) }
$$

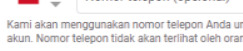

Alamat email pemulihan (opsional)

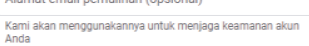

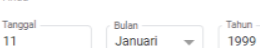

Tanogal lahir Anda

Januari - 1999

Gender
Wanita

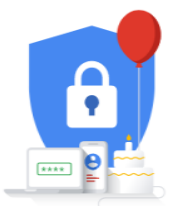

Gambar 2. Langkah pengisian informasi pribadi

\section{Langkah 3}

Menyetujui Syarat dan Ketentuan

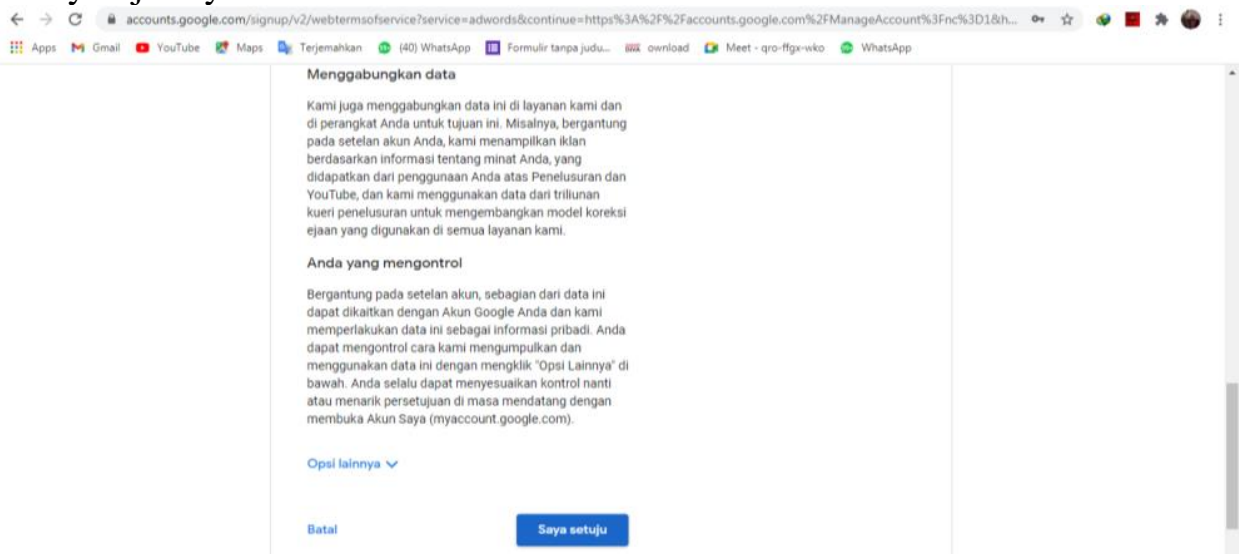

Gambar 3. Langkah persetujuan syarat dan ketentuan 


\section{Jurnal Pengabdian Kepada Masyarakat}

\section{BUGUH}

Dipublikasikan

Badan Pelaksana Kuliah Kerja Nyata

Universitas Lampung

Sekretariat Badan Pelaksana Kuliah Kerja Nyata, Universitas Lampung.

It. Prof. Dr. Soemantri Brojonegoro No. 1, Bandar Lampung 35145.

b. Pembuatan account Shopee

Langkah 1

Pengisian Data Diri

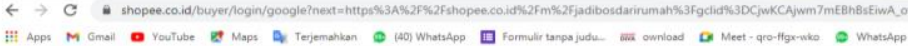

Shopee Daftar

Daftar Dengan Google

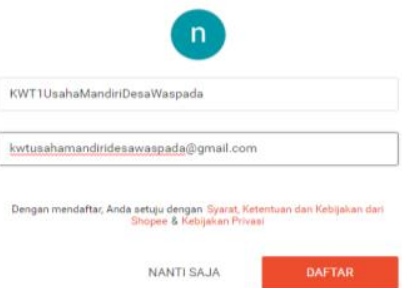

Gambar 4. Pengisian data diri shopee

\section{Langkah 2}

Pengisian Profil account

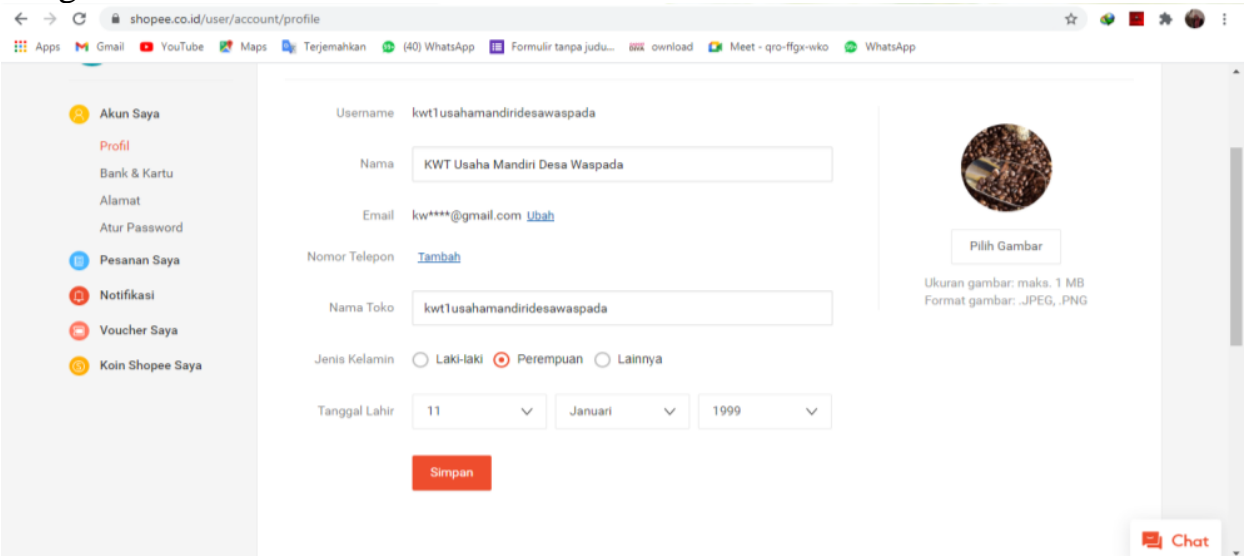

Gambar 5. Langkah pengisian profil account

c. Pembuatan account Facebook

\section{Langkah 1}

Pengisian data diri

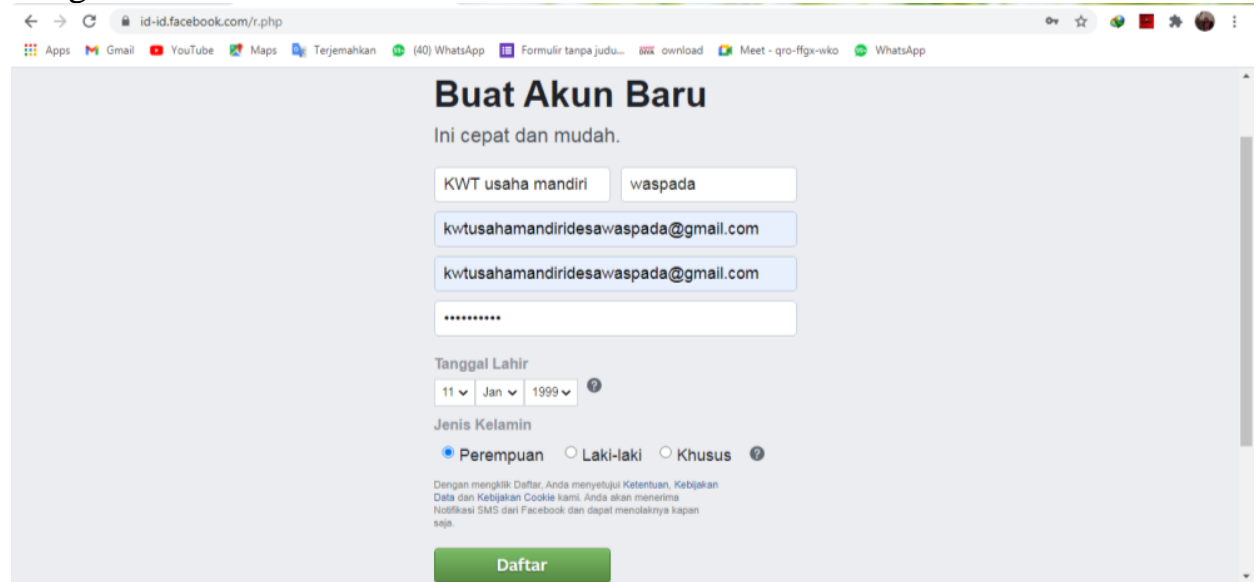

Gambar 6. Langkah pengisian data diri facebook 


\section{Jurnal Pengabdian Kepada Masyarakat}

\section{BUGUH}

Dipublikasikan

Badan Pelaksana Kuliah Kerja Nyata

Universitas Lampung

Sekretariat Badan Pelaksana Kuliah Kerja Nyata, Universitas Lampung.

Jl. Prof. Dr. Soemantri Brojonegoro No. 1, Bandar Lampung 35145.

\section{Langkah 2}

\section{Verifikasi email}

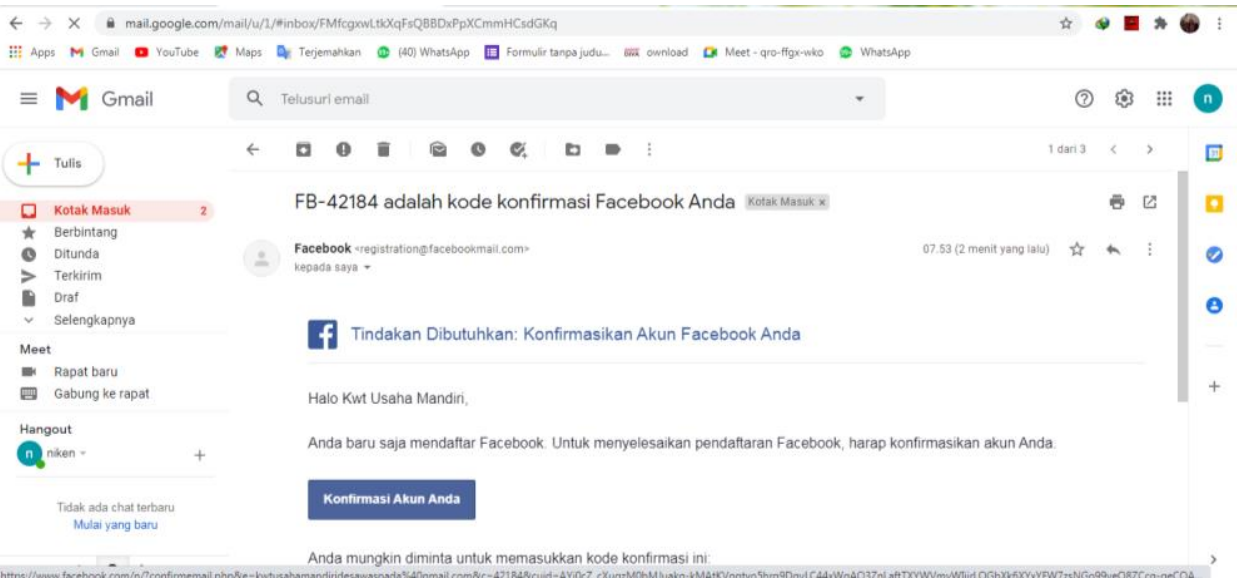

Gambar 7. Langkah verifikasi email

\section{Langkah 3}

Selesai

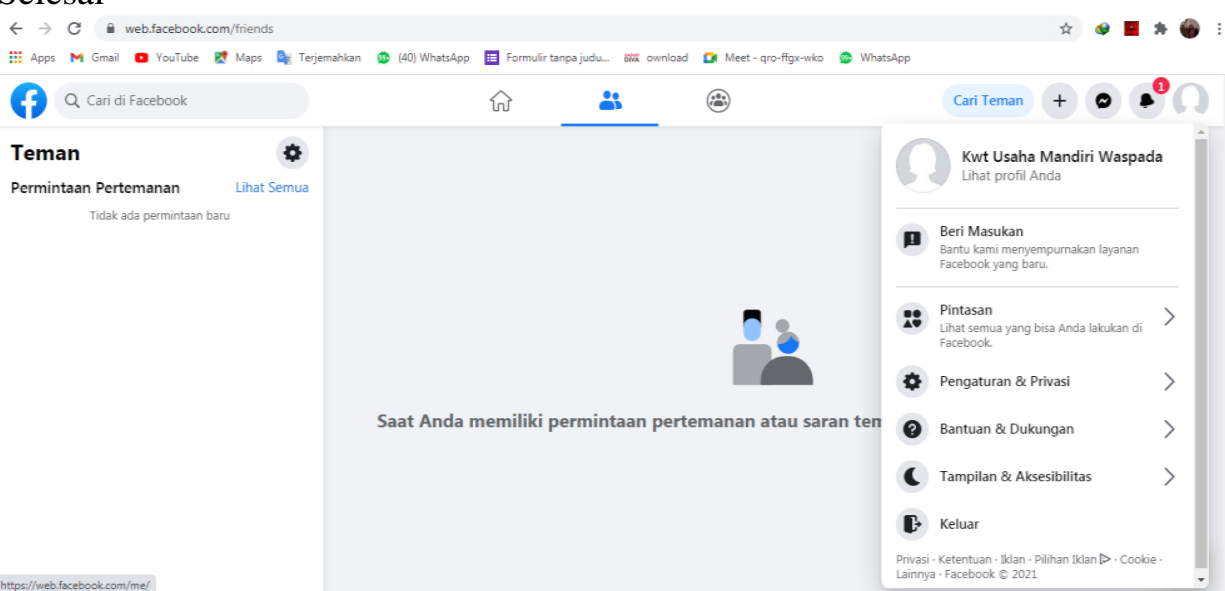

Gambar 8. Tampilan facebook

d. Pembuatan account Instagram

\section{Langkah 1}

Pengisian data diri

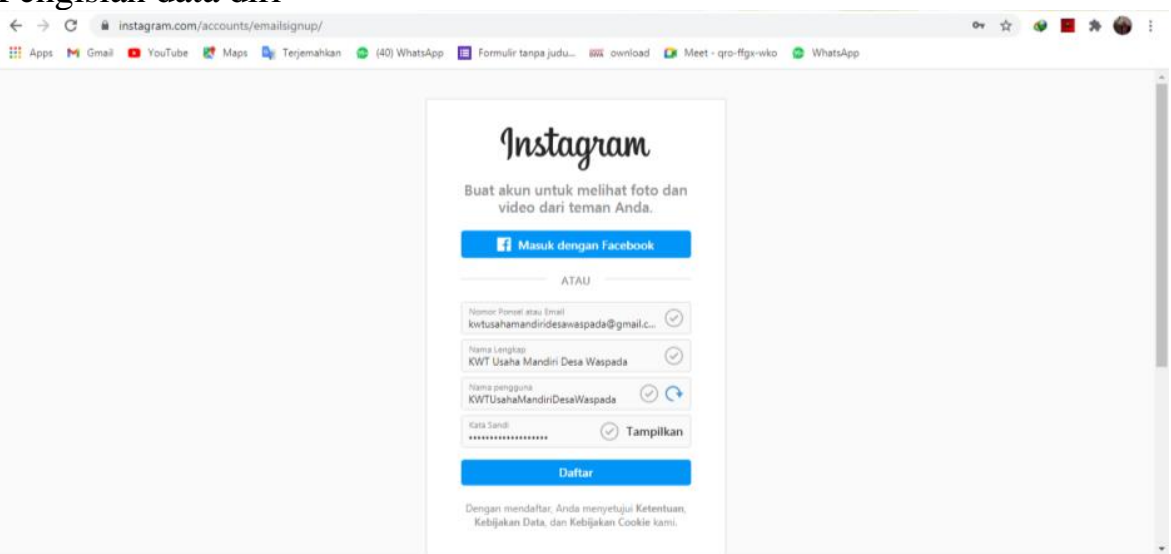

Gambar 9. Langkah pengisian data diri instagram 


\section{Jurnal Pengabdian Kepada Masyarakat BUGUH}

Dipublikasikan

Badan Pelaksana Kuliah Kerja Nyata

Universitas Lampung

Sekretariat Badan Pelaksana Kuliah Kerja Nyata, Universitas Lampung. Jl. Prof. Dr. Soemantri Brojonegoro No. 1, Bandar Lampung 35145.

\section{Langkah 2}

Memasukan kode verifikasi

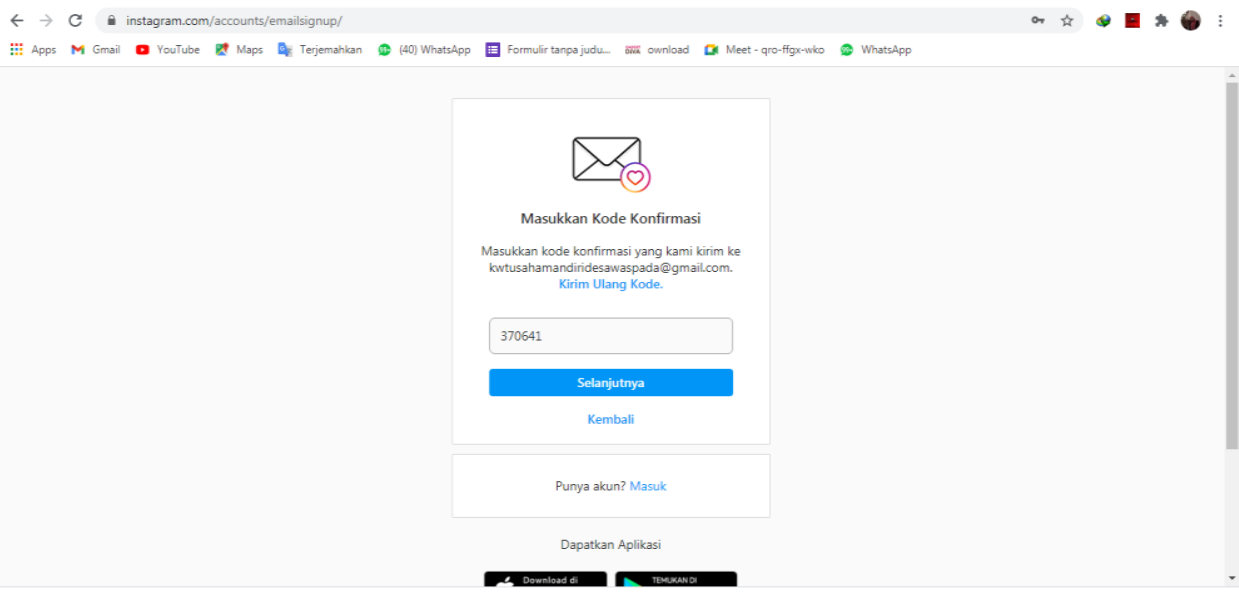

Gambar 10. Langkah verifikasi

\section{Langkah 3}

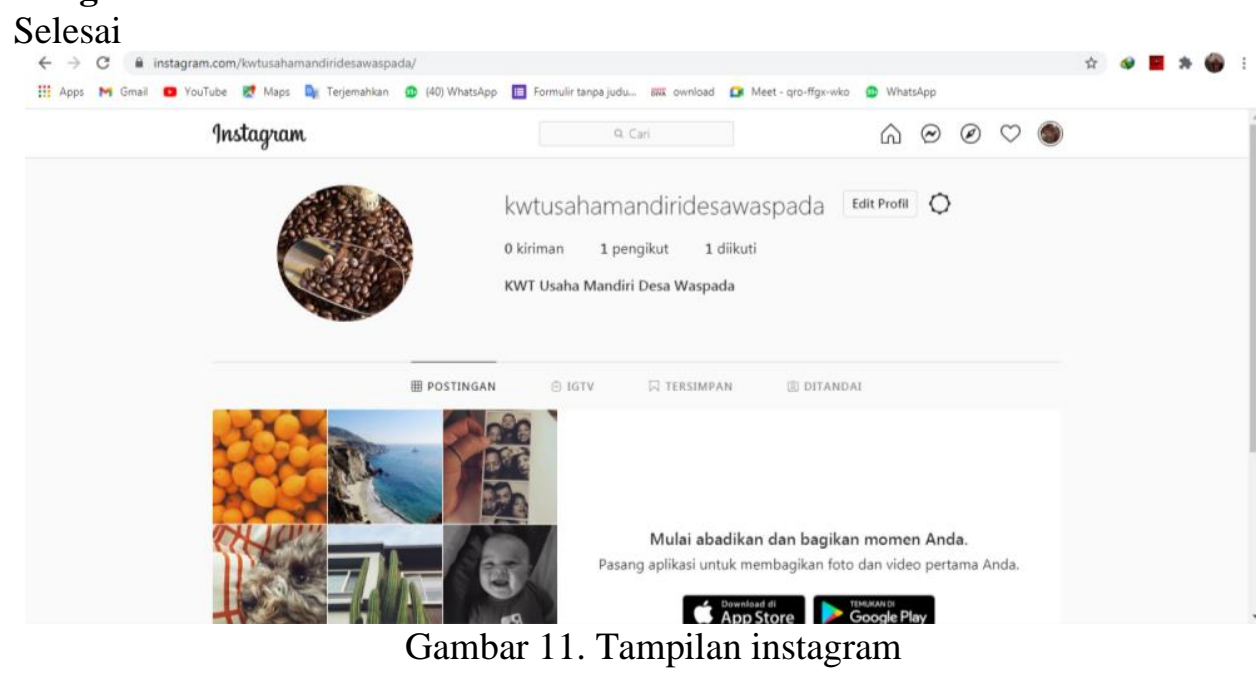

Hal serupa juga dilakukan untuk 2 Kelompok Wanita Tani lainnya.Dengan adanya pelatihan digital marketing dan praktik langsung pembuatan akun media sosial dan ecommerce diharapkan mampu medongkrak perekonomian desa Waspada khususnya untuk 3 Kelompok Wanita Tani yang ada di Desa Waspada. Sehingga Kelompok Wanita Tani dapat memberikan kesejahteraan kepada keluarga mereka terkhusus pada masa pandemi dan era teknologi seperti sekarang.

Menurut Loudon (1998), pengertian E-commerce adalah suatu proses yang dilakukan konsumen dalam membeli dan menjual berbagai produk secara elektronik dari perusahaan ke perusahaan lain dengan menggunakan komputer sebagai perantara transaksi bisnis yang dilakukan.

E-commerce sebetulnya dibagi menjadi enam golongan, yaitu:

1. Business to business (B2B) - Jenis di mana sebuah perusahaan menjual produk atau jasa kepada perusahaan lainnya. Dalam model ecommerce ini, biasanya pembeli memesan barang dalam jumlah besar. Contohnya adalah sebuah perusahaan yang membeli perlengkapan kantor dari sebuah produsen. 
Dipublikasikan

Badan Pelaksana Kuliah Kerja Nyata

Universitas Lampung

Sekretariat Badan Pelaksana Kuliah Kerja Nyata, Universitas Lampung.

Il. Prof. Dr. Scemantri Brojonegoro No. 1, Bandar Lampung 35145.

2. Business to consumer (B2C) - Dalam jenis ecommerce ini, sebuah perusahaan menjual produk atau jasa kepada konsumen. Pada umumnya, pelanggan dalam ecommerce B2C hanya mengecer. Jika anda pernah membeli dari suatu toko online, aktivitas tersebut termasuk dalam golongan ini.

3. Consumer to consumer $(\mathrm{C} 2 \mathrm{C})$ - Pernah menjual barang bekas ke orang lain yang membutuhkannya melalui internet? Aktivitas tersebut termasuk dalam ecommerce jenis ini. Dengan kata lain, C2C adalah transaksi online antara dua individu.

4. Consumer to business (C2B) - Berkebalikan dengan $\mathrm{B} 2 \mathrm{C}$, ecommerce $\mathrm{C} 2 \mathrm{~B}$ adalah skenario di mana seseorang menjual produk atau layanan kepada sebuah perusahaan. Seorang graphic designer, misalnya, menawarkan dan menjual logo buatannya kepada sebuah bisnis makanan.

5. Business to public administration (B2A) - Model ecommerce ini mirip dengan B2B, tetapi pelakunya adalah bisnis dan lembaga pemerintah. Contoh B2A adalah jasa pembuatan website untuk sistem administrasi online.

6. Consumer to public administration $(\mathrm{C} 2 \mathrm{~A})$ - Jenis ecommerce ini berjalan seperti C2B. Namun, transaksi dilakukan oleh individu dan lembaga pemerintah. Ecommerce dengan model C2A jarang ditemui di Indonesia. Jenis transaksi yang terjadi biasanya berbentuk jasa.

Pelatihan digitalisasi UMKM dan pembuatan akun E-Commerce dilaksanakan pada tanggal 18 Februari 2021 dan 02 Maret 2021. Pelatihan dan pembuatan akun ECommerce ini ditujukan untuk UMKM KWT Usaha Mandiri, Kenanga, dan Cempaka. ECommerce yang kami buatkan diantaranya Shopee, Facebook dan Instagram. Berdasarkan 6 golongan E-Commerce yang tersedia tersebut, maka Shopee, Facebook dan Instagram termasuk dalam Business to consumer (B2C), dimana jenis ecommerce ini, menjual produk atau jasa kepada konsumen. Seperti toko Online.

Dari beberapa fitur dan keuntungan yang ditawari oleh E-Commerce kepada konsumen, maka E-Commerce sangat membantu sekali dalam melakukan promosi jual beli produk, seperti Kopi Tugu Waspada yang dijalankan oleh KWT Usaha Mandiri, Kue Lampung oleh KWT Kenanga, dan Dodol oleh KWT Cempaka. Adanya pelatihan dan pembuatan E-Commerce setiap KWT maka dapat membantu dalam pemasaran produk dan justru lebih memberikan nilai tambah serta menghemat beberapa proses pemasaran, terutama disaat pandemi seperti ini yang menuntut wirausaha harus terus memberikan ide-ide baru untuk kemajuan usaha yang dijalankan.

Kemudian, dari beberapa fitur dan keuntungan yang ditawari oleh E-Commerce kepada konsumen, maka E-Commerce juga sangat membantu sekali dalam melakukan promosi jual beli produk, seperti Kopi Tugu Waspada yang dijalankan oleh KWT Usaha Mandiri, Jajanan Pasar Tradisional dan Kue Lampung oleh KWT Kenanga, dan Dodol oleh KWT Cempaka. Adanya pelatihan dan pembuatan E-Commerce setiap KWT maka dapat membantu dalam pemasaran produk dan justru lebih memberikan nilai tambah serta menghemat beberapa proses pemasaran karena E-Commerce dapat merambah dunia pasar lebih luas, terutama disaat pandemi seperti ini yang menuntut wirausaha harus terus memberikan ide-ide baru untuk kemajuan usaha yang dijalankan. Pelatihan digitalisasi UMKM dan pembuatan akun E-Commerce inipun masih kami pantau terkait dengan perkembangannya, dan menjadikan perbandingan dengan penjualan offline. 


\section{Jurnal Pengabdian Kepada Masyarakat BUGUH}

Dipublikasikan

Badan Pelaksana Kuliah Kerja Nyata

Universitas Lampung

Sekretariat Badan Pelaksana Kuliah Kerja Nyata, Universitas Lampung.

Il. Prof. Dr. Scemantri Brojonegoro No. 1, Bandar Lampung 35145.
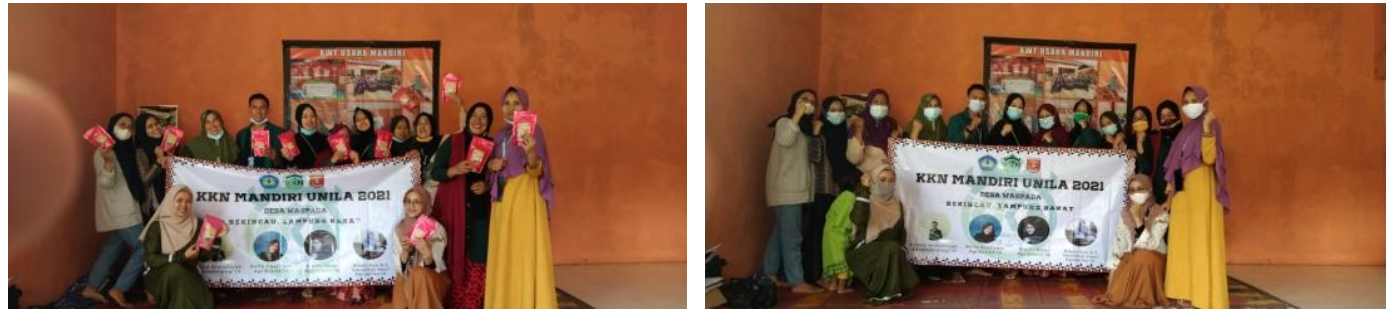

Gambar 12. Pelatihan digitalisasi UMKM dan pembuatan akun E-commerce

\section{Kesimpulan}

Pelatihan digitalisasi UMKM dan pembuatan akun E-Commerce dilaksanakan pada tanggal 18 Februari 2021 dan 02 Maret 2021. Pelatihan dan pembuatan akun ECommerce ini ditujukan untuk UMKM KWT Usaha Mandiri, Kenanga, dan Cempaka. ECommerce yang kami buatkan diantaranya Shopee, Facebook dan Instagram. Berdasarkan 6 golongan E-Commerce yang tersedia, maka Shopee, Facebook dan Instagram termasuk dalam Business to consumer (B2C), dimana jenis ecommerce ini, menjual produk atau jasa kepada konsumen. Seperti toko Online.

Kemudian, dari beberapa fitur dan keuntungan yang ditawari oleh E-Commerce kepada konsumen, maka E-Commerce juga sangat membantu sekali dalam melakukan promosi jual beli produk, seperti Kopi Tugu Waspada yang dijalankan oleh KWT Usaha Mandiri, Kue Lampung oleh KWT Kenanga, dan Dodol oleh KWT Cempaka. Adanya pelatihan dan pembuatan E-Commerce setiap KWT maka dapat membantu dalam pemasaran produk dan justru lebih memberikan nilai tambah serta menghemat beberapa proses pemasaran karena E-Commerce dapat merambah dunia pasar lebih luas, terutama disaat pandemi seperti ini yang menuntut wirausaha harus terus memberikan ide-ide baru untuk kemajuan usaha yang dijalankan. Pelatihan digitalisasi UMKM dan pembuatan akun ECommerce inipun masih kami pantau terkait dengan perkembangannya, dan menjadikan perbandingan dengan penjualan ofline .

\section{Ucapan Terima Kasih}

Tim pengabdian Kuliah Kerja Nyata Universitas Lampung mengucapkan terima kasih kepada seluruh pihak yang terlibat yaitu kepala dusun, ibu-ibu PKK, dan Kaderisasi Posyandu Desa Waspada, Kec.Sekincau, Kab. Lampung Baratyang telah membantu dan dukungan kepada kami untuk melaksanakan kegiatan secara optimal.

\section{Daftar Pustaka}

Idah, Y. M., \& Pinilih, M. (2020). Strategi Pengembangan Digitalisasi UMKM. Prosiding Seminar Nasional Dan Call for Papers "Pengembangan Sumber Daya Pedesaan Dan Kearifan Lokal Berkelanjutan IX," 9(1), 195-204.

Kenneth J, Laudon, Jane P. Laudon. 1998. Sistem Informasi Manajemen: The Digital Firm, International Edition. New Jersey. Pentise Hall International Inc.

Qamari, I. N., Herawati, R., Handayani, S., Junaedi, F., \& Jati, L. J. (2021). Digitalisasi Bisnis Kelompok Umkm Di Desa Poncosari, Bantul, Yogyakarta, Indonesia. Prosiding Seminar Nasional Program Pengabdian Masyarakat, 310-315. https://doi.org/10.18196/ppm.32.211 